\title{
Ultrastructural immunocytochemical localisation of lysozyme in human bronchial glands
}

\author{
DENISE BOWES AND BRYAN CORRIN \\ From Midhurst Medical Research Institute, Midhurst, Sussex GU29 OBL and the Department of \\ Morbid Anatomy, St. Thomas' Hospital Medical School, London SE1 7EH
}

Bowes, Denise and Corrin, B. (1977). Thorax, 32, 163-170. Ultrastructural immunocytochemical localisation of lysozyme in human bronchial glands. An immunocytochemical unlabelled antibody method using rabbit antihuman lysozyme, antirabbit immunoglobulin, and soluble rabbit antihorseradish peroxidase/horseradish peroxidase complexes was used to study the fine structural distribution of lysozyme in human bronchial glands. None was identified in mucous cells but there was heavy staining of the serous cell granules. The serous cell granules were not stained uniformly, suggesting the presence of other secretory products but lysozyme secretion appears to be a major function of these cells. The pathological implications of this are discussed.

Although the bronchial glands are of mixed (seromucous) type, medical attention has recently been concentrated on mucus secretion, and the serous component of these glands has been relatively neglected. This is understandable as the major diseases involving the bronchial glands are characterised by excessive or hyperviscous mucus secretion. In chronic bronchitis, for example, the bronchial glands not only enlarge but become largely mucous in character. The resultant diminution of serous secretion is generally suspected of increasing sputum viscosity but little consideration has so far been given to other aspects of serous cell function. Serous secretions in other organs, for example, salivary glands and pancreas, are generally rich in enzymes, and recently lysozyme, an important nonspecific antibacterial enzyme (Fleming, 1922), has been identified in the serous but not the mucous bronchial glands by immunohistological methods (Klockars and Reitamo, 1975; Mason and Taylor, 1975). In view of the reduction of serous relative to mucous acini in chronic bronchitis, this finding would appear to hold important implications in regard to the frequent bacterial infections which characterise this disease. We have therefore used an immunoperoxidase technique for the identification of lysozyme to confirm the distribution of this enzyme in the bronchial glands and to extend these studies to the subcellular level with the electron microscope. In particular, we were inter- ested in the topographical relationship of lysozyme to the characteristic 'secretory' granules evident in the apical poles of the serous cells.

\section{Material and methods}

Samples of fresh human bronchial mucosa were obtained from surgical specimens which were generally removed because of cancer. Small pieces were fixed for 1-2 hours in 2.5\% glutaraldehyde or $4 \%$ methanol-free formaldehyde in $0.1 \mathrm{M}$ sodium cacodylate buffer containing $7 \cdot 2 \%$ sucrose at $\mathrm{pH} 7.4$ and $4^{\circ} \mathrm{C}$. They were rinsed overnight in buffer, dehydrated in graded ethanols, and embedded in Epon 812. Some samples were postfixed in osmium tetroxide, and thin sections of these were stained with uranyl acetate and lead citrate before electron microscopic examination, but these steps were omitted from the lysozyme localisation procedure.

Immunocytochemical localisation of lysozyme was carried out by an unlabelled antibody method (Erlandsen et al., 1974) using rabbit antihuman lysozyme and Dakopatts soluble rabbit antihorseradish peroxidase/horseradish peroxidase complex, both obtained from Mercia Diagnostics. Paramount Industrial Estate, Sandown Road, Watford WD2 4XA, Hertfordshire. Thin sections were picked up on uncoated nickel grids and etched for $10 \mathrm{~min}$ on drops of $10 \%$ hydrogen peroxide to facilitate the diffusion of reagents. 
The grids were dipped into distilled water at least three times and treated with $10 \%$ normal sheep serum in tris-buffered saline for $10 \mathrm{~min}$ to minimise the non-specific absorption of antisera. After this and between subsequent steps the sections were rinsed thoroughly with $1 \%$ normal sheep serum in tris-buffered saline. The immunocytochemical methods comprised floating the sections for $3 \mathrm{~min}$ on drops of each of the following antisera:

(a) rabbit antihuman lysozyme antiserum at dilutions of $1: 2,1: 5$, or $1: 10$;

(b) goat or sheep antirabbit IgG antiserum diluted $1: 10$

(c) soluble PAP complex diluted $1: 10$ or $1: 50$. Localisation of peroxidase/antiperoxidase complex was identified by incubating the grids for $3 \mathrm{~min}$ in $0.05 \mathrm{M}$ tris buffer $(\mathrm{pH} \mathrm{7.6})$ containing $12 \mathrm{mg} / \mathrm{dl} \mathrm{3,3}$-diaminobenzidine tetrahydrochloride (Sigma) and freshly prepared $0.0025 \%$ hydrogen peroxide. The grids were washed in distilled water and floated on drops of $2-4 \%$ osmium tetroxide for $20 \mathrm{~min}$ to increase the electron density of the peroxidase reaction product. The grids were then washed thoroughly in distilled water, dried, and $\overrightarrow{\vec{\rho}}$ examined in a JEOL electron microscope without any further counterstaining. Each experiment was $\frac{}{\circ}$ controlled for specificity, method, and sensitivity. $\frac{\bar{\sigma}}{\sigma}$ In the specificity control normal rabbit serum was $\widehat{\Phi}$ substituted for the rabbit antihuman lysozyme antiserum. In the method control normal goat or ${ }^{\infty}$ sheep serum was substituted for goat or sheep? antirabbit IgG antiserum, and in the sensitivity $\vec{A}$ control the rabbit antihuman lysozyme antiserum was diluted $1: 1000$ and $1: 100000$. An etching $\overrightarrow{\vec{*}}$ control omitted the initial treatment of the sections with $10 \%$ hydrogen peroxide.

\section{Results}

Serous and mucous cells were readily distin- $\stackrel{\circ}{\supset}$ guished, even in unstained negative control $\vec{D}$ lysozyme preparations. With double fixation and을 heavy metal counterstaining it was evident that the serous cells had many electron dense discrete $\vec{\theta}$ granules whereas the mucous cell granules were. $N$ less electron dense, larger, and frequently fused with each other (Fig. 1). The mucous granules

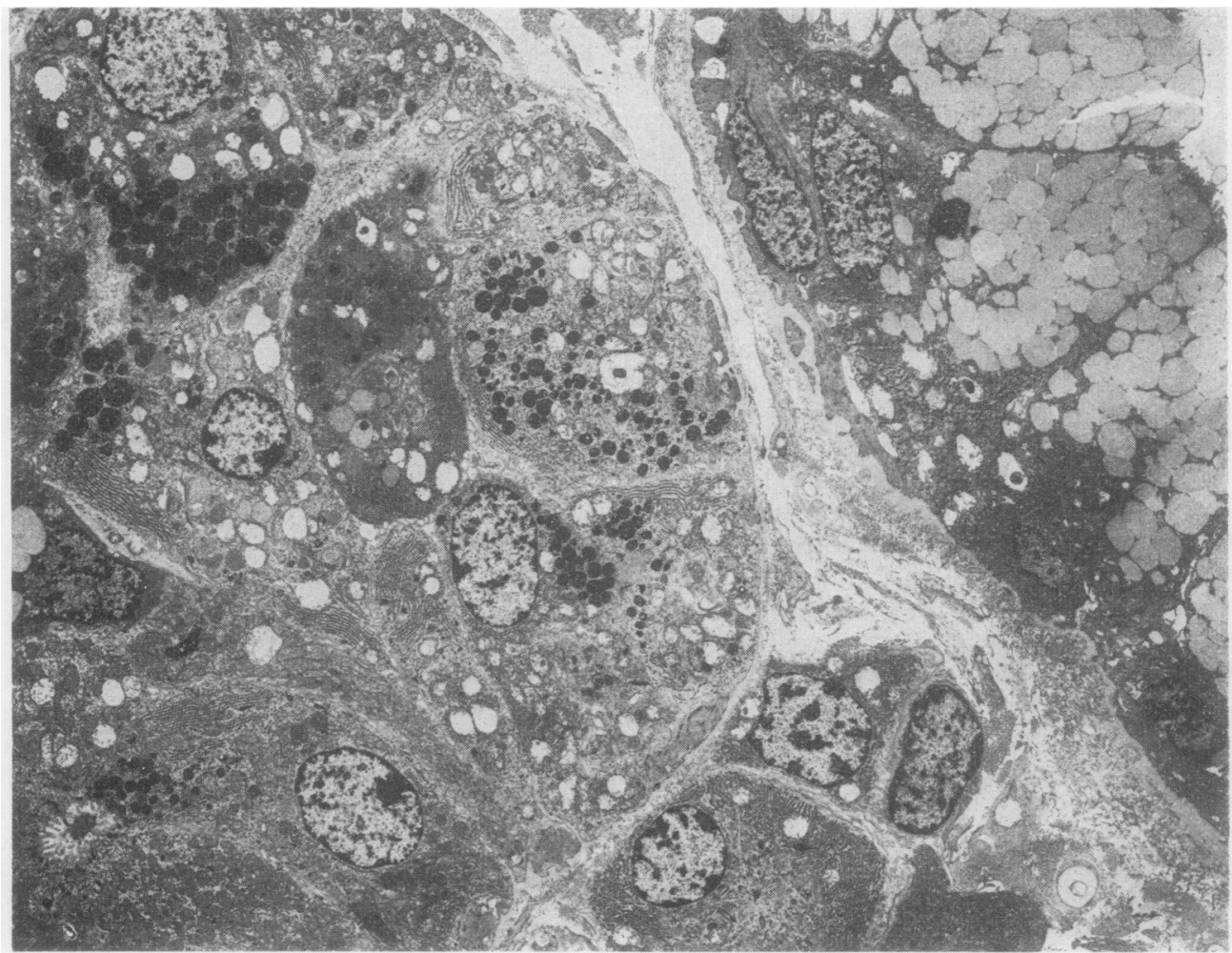

Fig. 1 Mucous gland to the right, serous gland to the left. Tissue fixed in glutaraldehyde and osmium tetroxide, section stained with lead citrate and uranium acetate. $(G O L U) \times 2000$. 
were frequently observed discharging into the lumen but exocytosis was not identified in the case of the serous cell. Both cell types contained a variable amount of rough endoplasmic reticulum and Golgi apparatus, depending on the phase of the secretory cycle.

The serous cell granules were spherical or ovoid, membrane bound, and electron dense. They were usually concentrated at the apical pole of the cell and generally measured $300-1000 \mathrm{~nm}$ in diameter but occasionally reached up to $2000 \mathrm{~nm}$. The electron density of the serous cell granules varied but generally they were homogeneous. However, some granules possessed an extremely electron dense small central core (Fig. 2), while in others there was a crescentic electron dense outer halo (Fig. 3). Smaller electron dense bodies (about $50 \mathrm{~nm}$ diameter) of irregular shape were also observed in the serous cells. These were regarded as lysosomes. The cytoplasm of the serous cells also contained moderate numbers of mitochondria and the free surfaces bore microvilli.

Lysozyme staining showed heavy deposition of reaction product in the serous cell granules. No lysozyme was detected in the mucous cells. The serous cell granules varied in their lysozyme content. The majority were uniformly stained (Fig. 4) but others contained no reaction product (Fig. 5) and some showed a non-uniform distribution of lysozyme. A small central area of negative staining was evident in some granules (Fig. 6) while in others there was a negatively stained peripheral halo (Fig. 7). The only other site of lysozyme localisation noted was in the small irregular dense bodies which probably represent lysosomes. No reaction product was noted in the endoplasmic reticulum or Golgi apparatus. No reaction was obtained in the specificity or method controls, very little in the $1: 1000$ sensitivity control, and none at $1: 100000$ dilution of the antilysozyme antiserum within the three-minute incubation period. The etching controls were generally positive, indicating that this step is unnecessary.

\section{Discussion}

These studies confirm the presence of lysozyme in the serous acini of the bronchial submucosal

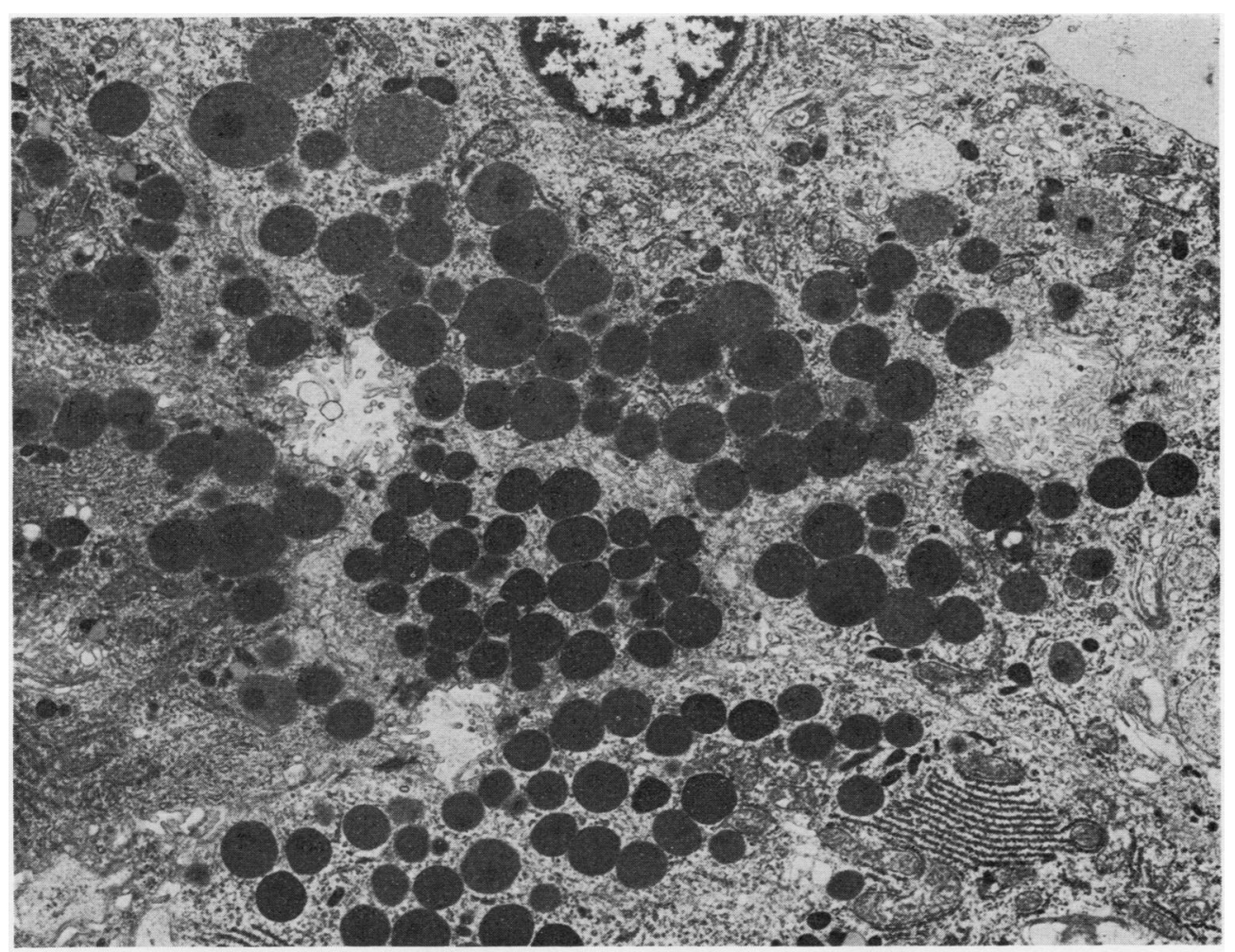

Fig. 2 Serous acinus showing variation in the electron density of the secretory granules, some of which have an extremely dense central core. $(G O L U) \times 5200$. 
glands and its absence from the mucous acini. They also demonstrate that within the serous cells lysozyme is found in the electron dense bodies which fill the apical poles of these cells. As in earlier studies (Meyrick and Reid, 1970), extrusion of these bodies into the glandular lumina was not observed, but the bodies are nevertheless regarded as secretory granules. Our findings suggest that lysozyme secretion is a major function of the serous cells because the reaction product is found distributed uniformly throughout most secretory granules or occupying a major part of them. The serous cells may therefore be considered part of the bronchial defence system against infection.

The absence of lysozyme from some serous cell granules and its irregular distribution within others suggests the presence of other secretory products, and it is known that the bronchial serous cells contain small amounts of glycoprotein. This is comparatively scanty and differs histochemically from that in the pure mucous cells (Lamb and Reid, 1970). It may provide a mucinous envelope for the main secretory product, as is suggested by $\overrightarrow{\bar{S}}$ those micrographs demonstrating a peripheral rim 0 devoid of lysozyme, or constitute the very small $\frac{0}{\partial}$ lysozyme-free central core seen within other $\frac{\bar{m}}{\vec{s}}$ secretory granules. The fine structural study of $\overrightarrow{\mathbb{D}}$ glycoprotein distribution within the serous cell awaits further study.

As our material was drawn from routine pneu- $\overrightarrow{0}$

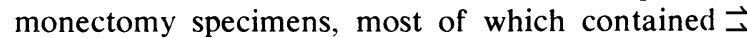
tumours elsewhere in their airways, it cannot be $\stackrel{\omega}{\omega}$ regarded as completely normal. Nevertheless the $\overrightarrow{\overrightarrow{\vec{z}}}$ areas selected for this study showed no histological $\underset{\omega}{x}$ abnormality and there is no reason to suppos $2 \stackrel{N}{N}$ that the underlying disease would materially alter ? the distribution of lysozyme in these apparently $\vec{\omega}$ normal areas. None of our cases showed histo- 0 logical evidence of chronic bronchitis but it does? not appear unreasonable to presume that in this disease the reduction of serous relative to mucous acini would result in a low concentration of lysozyme in the secretion of the bronchial glands. Alveolar macrophages leaving the lung in the. bronchial lining layer may compensate to some

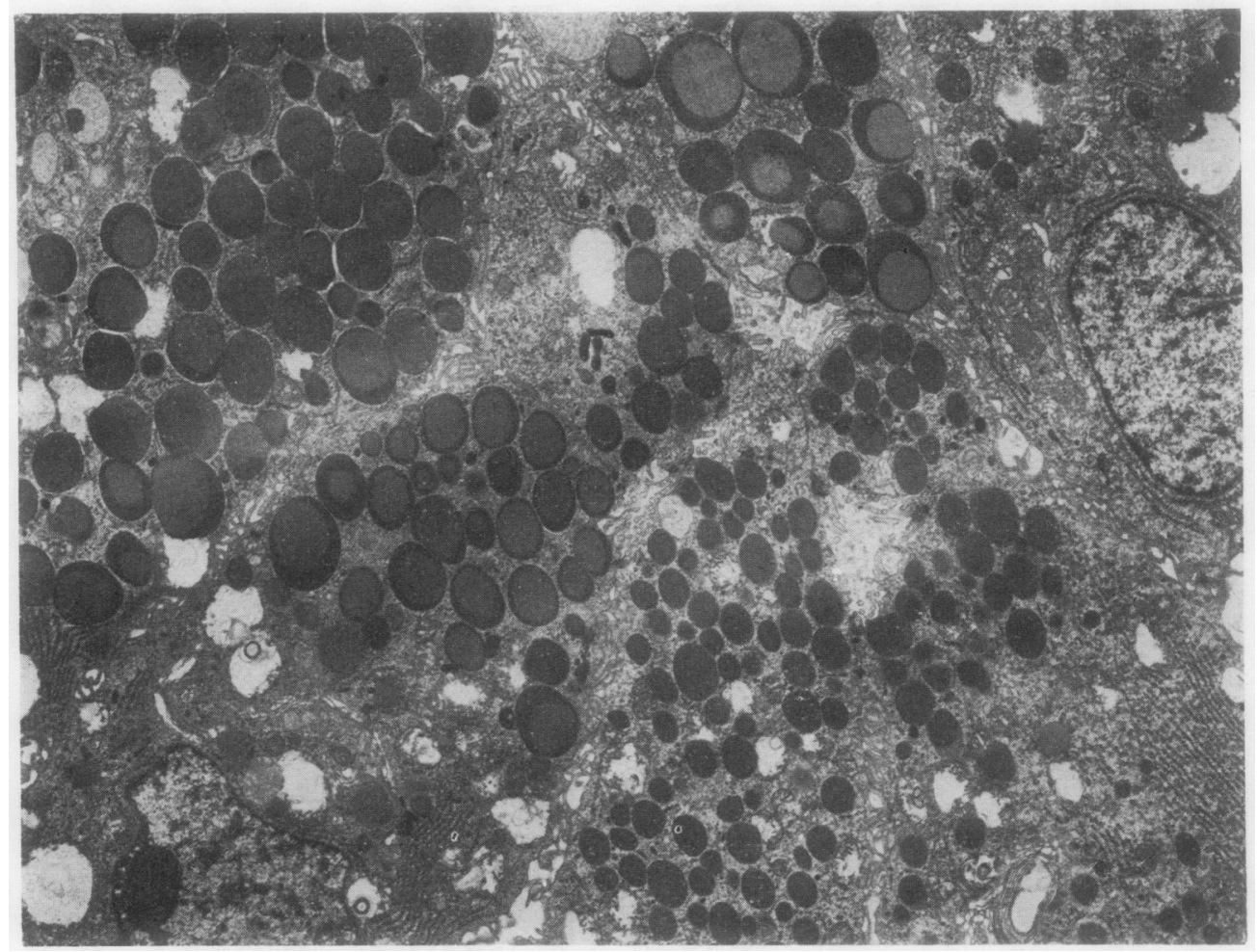

Fig. 3 Serous acinus showing increased electron density at the periphery of some secretory granules. $(G O L U) \times 4800$. 


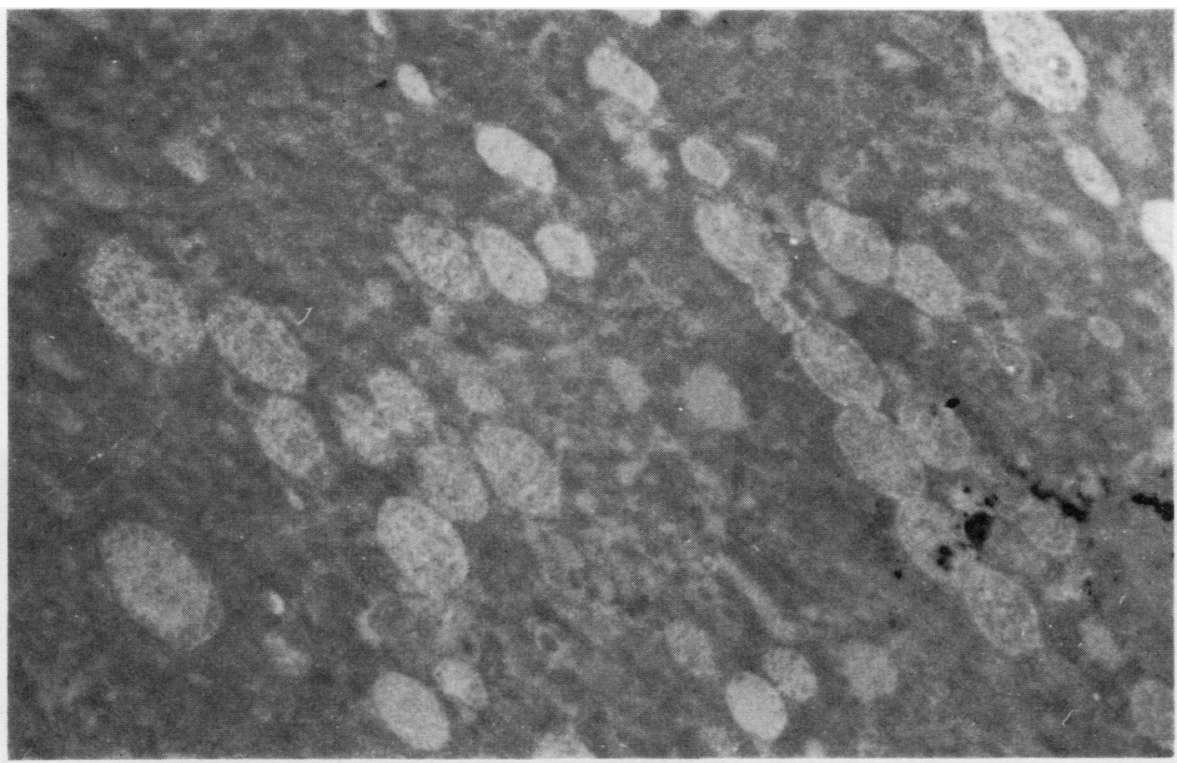

(a)

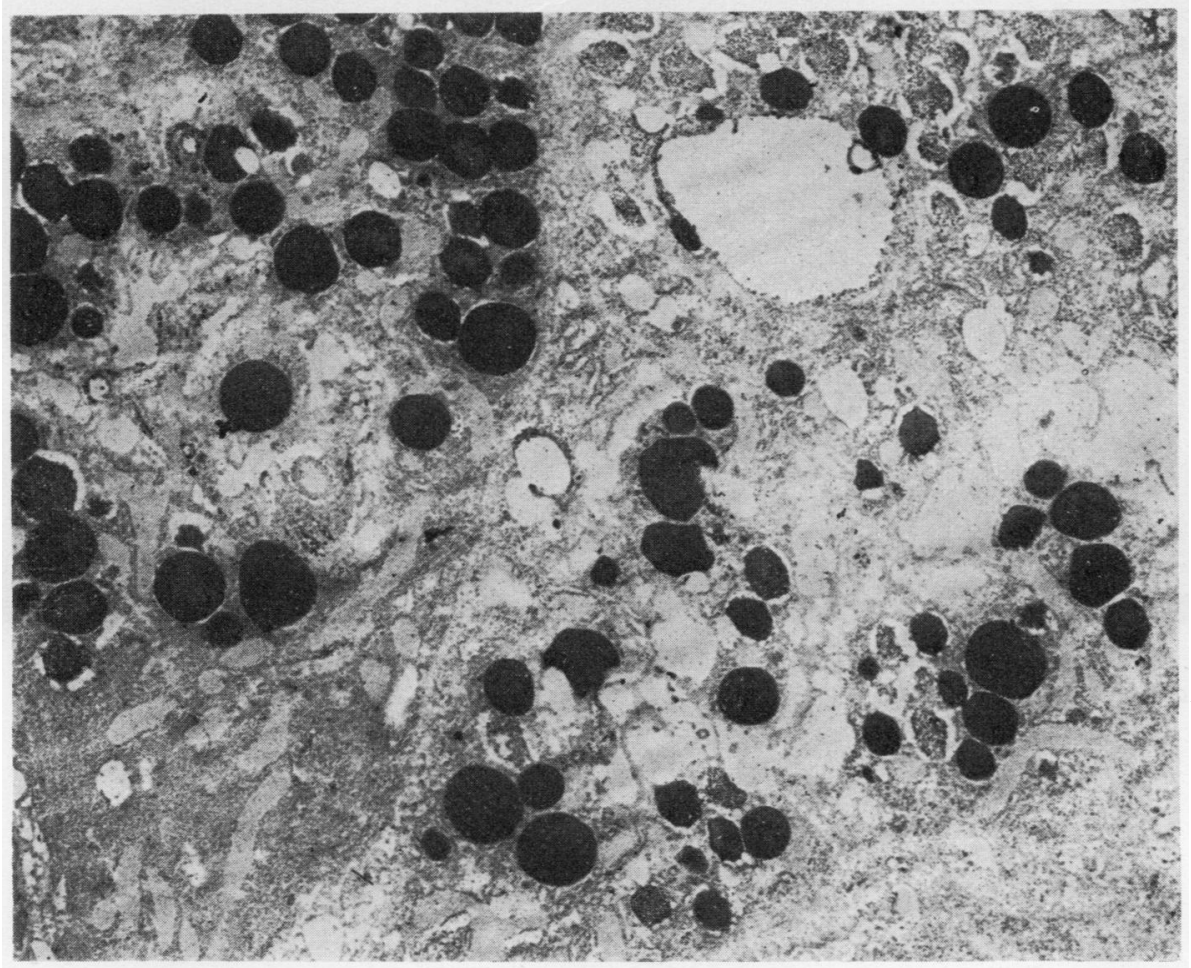

(b)

Fig. 4 (a) Lysozyme identification negative control. In contrast to the previous figures this and the succeeding figures depict unstained (no lead or uranium) sections of tissue fixed only in glutaraldehyde. $\times 5000$. (b) Lysozyme identification. There is heavy uniform deposition of the antilysozyme immunoperoxidase reaction product in all the serous secretory granules. $\times 5500$. 


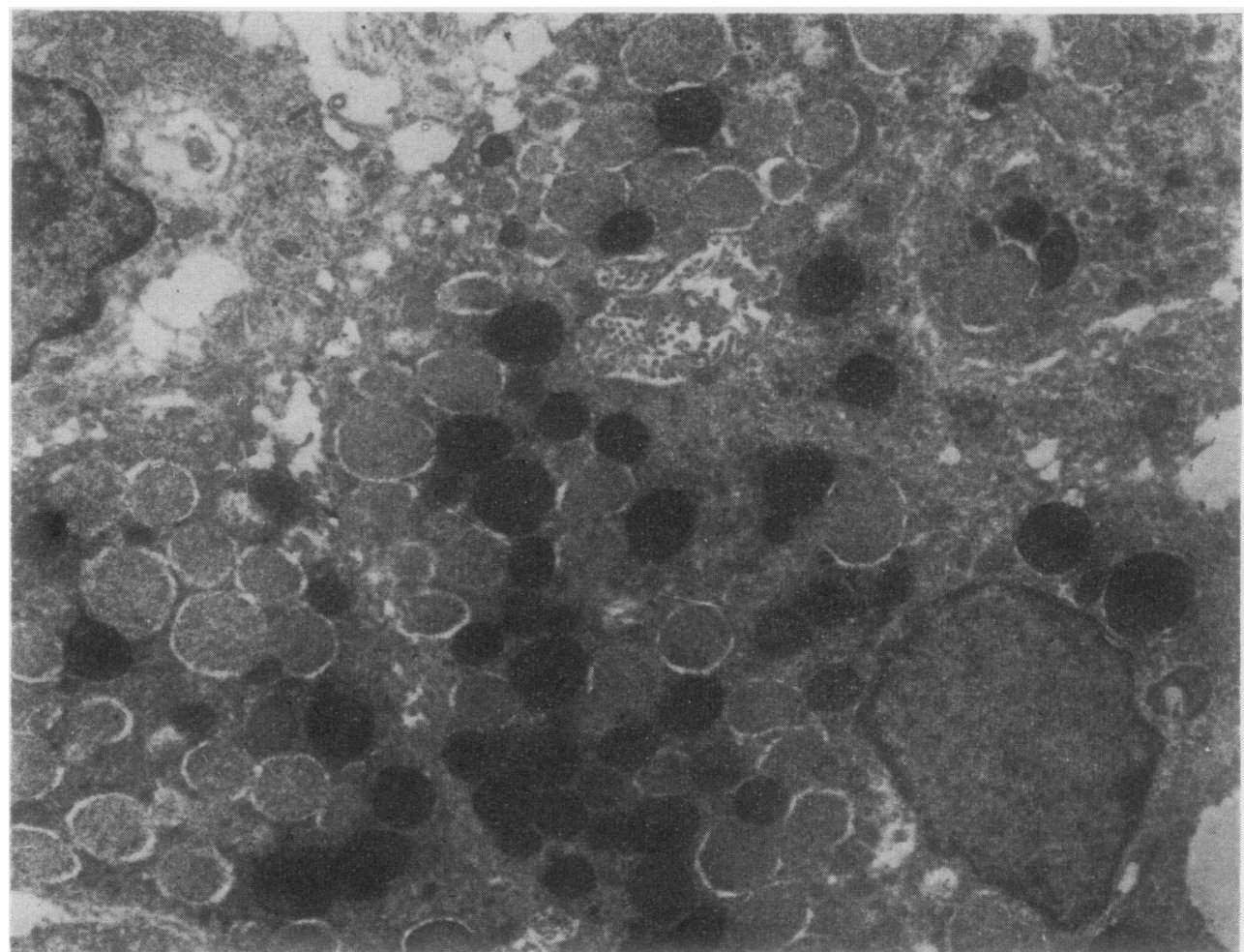

Fig. 5 Lysozyme identification. Some serous cell granules contain lysozyme but others are negative. $\times 6500$. 


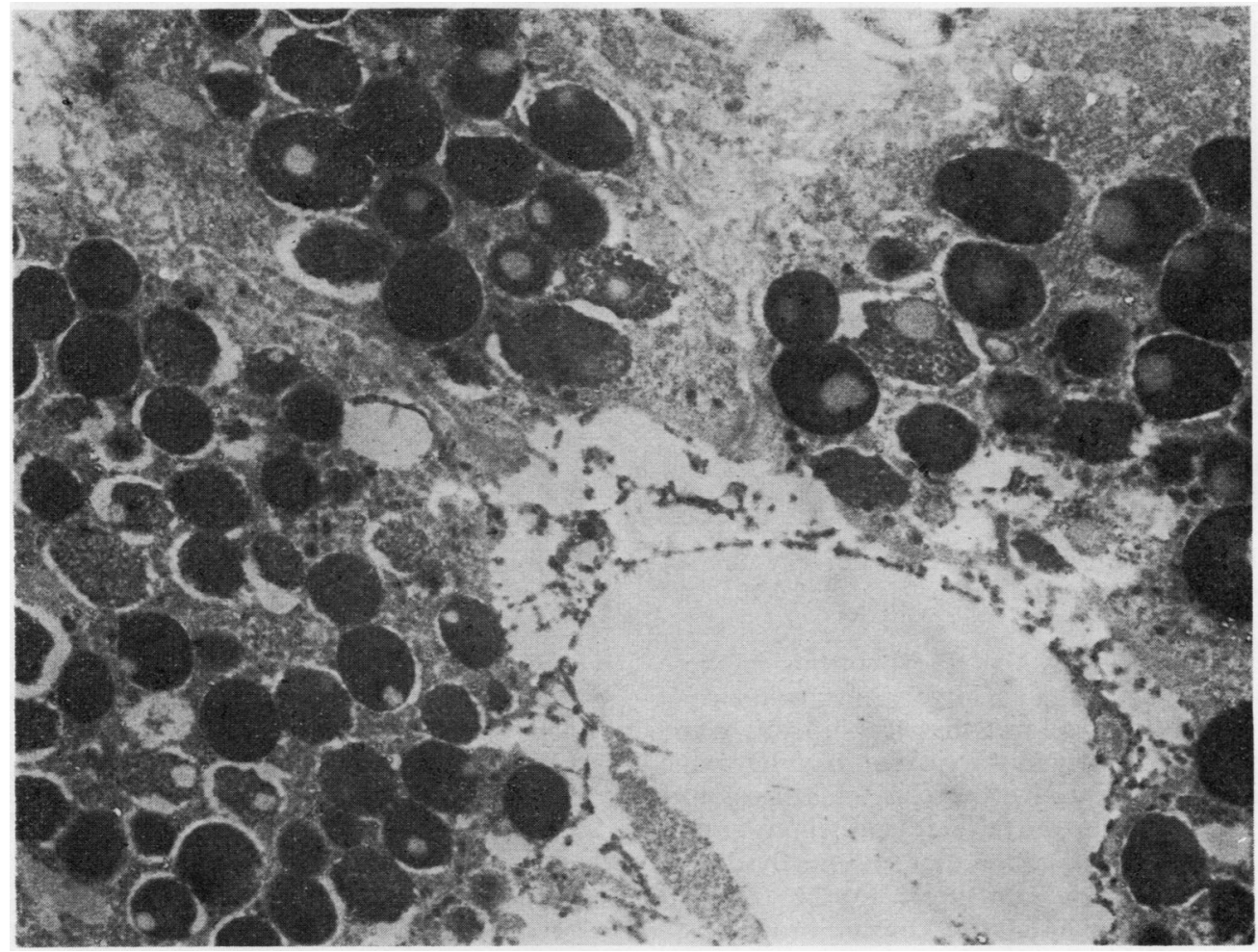

Fig. 6 Lysozyme identification. The serous cell granules contain much lysozyme but many show a central lysozyme-free area. Compare with Fig. $2 . \times 12000$. 


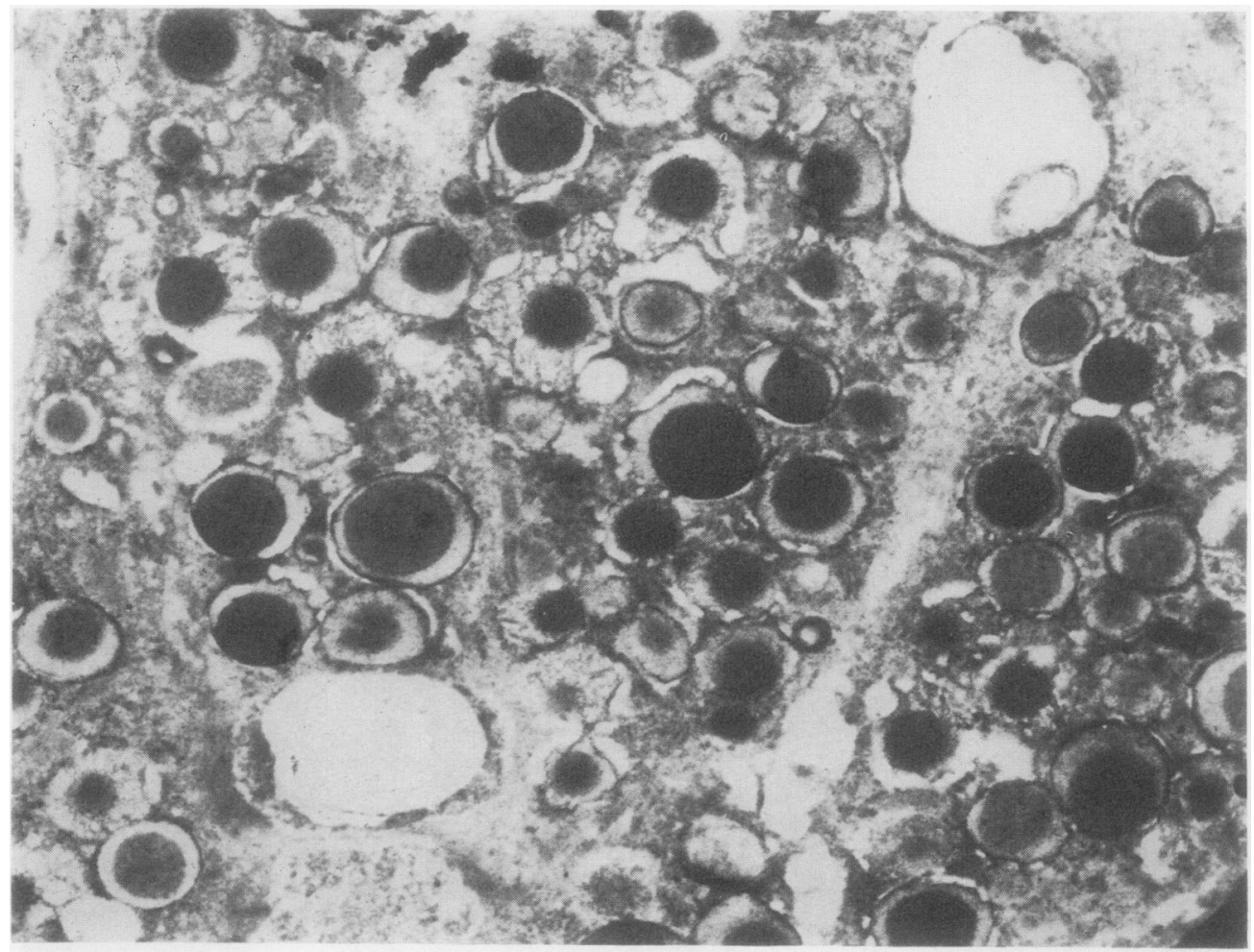

Fig. 7 Lysozyme identification. Heavy staining of the serous granules except for a peripheral outer rim. Compare with Fig. 3. $\times 10000$.

degree but it is likely that the lysozyme in these phagocytic cells remains largely intracellular. It seems possible, therefore, that the mucous gland hyperplasia in chronic bronchitis has lysozyme depletion as its negative correlate, just as goblet cell proliferation in the surface epithelium entails loss of ciliary activity. Low sputum lysozyme concentration would contribute to the frequent infections which characterise chronic bronchitis.

\section{References}

Erlandsen. S. L., Parsons. J. A., and Taylor. T. D. (1974). Ultrastructural immunocytochemical localization of lysozyme in the Paneth cells of man. Journal of Histochemistry and Cytochemistry, 22, 4() $1-413$.

Fleming, A. (1922). On a remarkable bacteriolytic element found in tissues and secretions. Proceedings of the Royal Society, Series B., 93, 206-317.

Klockars. M. and Reitamo, S. (1975). Tissue distribution of lysozyme in man. Journal of Histochemistry and Cytochemistry, 23, 932-940.

Lamb, D. and Reid, L. (1970). Histochemical and autoradiographic investigation of the serous cells of the human bronchial glands. Journal of
Pathology, 100, 127-138.

Mason, D. Y. and Taylor, C. R. (1975). The distribu! tion of muramidase (lysozyme) in human tissues. Journal of Clinical Pathology, 28, 124-132.

Meyrick, B. and Reid, L. (1970). Ultrastructure of cells in the human bronchial submucosal glands. Journal of Anatomy, 107, 281-299.

Requests for reprints to: Dr B. Corrin, Department of Medical Anatomy, St. Thomas' Hospital Medicalo School, London SE1 7EH.

\section{Note added in proof}

The last paragraph includes an assumption which is possibly invalid. It is suggested that the lysozyme in alveolar macrophages is largely retained for intracellular digestion, but Gordon et al. (1974) have shown that most of the lysozyme in otheres mononuclear phagocytes is secreted to the exterior.

\section{Reference}

Gordon, S., Todd, J. and Cohn, Z. A. (1974). In $\frac{\%}{\Phi}$ vitro synthesis and secretion of lysozyme by mononuclear phagocytes. Journal of Experimental Medi cine, 139, 1228. 